\title{
COERÊNCIA ENTRE SABERES E PRÁTICAS DE UMA PROFESSORA ALFABETIZADORA BEM SUCEDIDA
}

\author{
Lenita Carmello de ALMEIDA ${ }^{1}$ \\ Dirce Charara MONTEIRO ${ }^{2}$
}

RESUMO: Apesar de investimentos na área educacional, o Brasil ainda continua com sérios problemas, principalmente nas questões referentes à alfabetização. Investigar os saberes e práticas de profissionais bem sucedidos pode fornecer diretrizes relevantes para o trabalho do professor alfabetizador, foco desta pesquisa. Nesse contexto, buscouse analisar a coerência entre saberes e atividades que configurem a prática pedagógica de uma professora alfabetizadora bem sucedida, considerando as diferentes naturezas dos saberes e os condicionantes da prática pedagógica. Trata-se de um estudo de caso que constou das seguintes etapas: a) busca de fundamentos; b) duas entrevistas semiestruturadas com a professora; c) observação de suas aulas; d) análise do seu material didático bem como de seu planejamento. Nem sempre foi possível correlacionar as práticas observadas aos saberes identificados, até porque nem todos os saberes necessariamente possuem uma contrapartida prática. A prática do professor, por sua vez, com todos os seus condicionantes, apesar do planejamento, nem sempre pôde ser relacionada a um saber no contexto nem sempre previsível da sala de aula. Feitas essas ressalvas, dentre os resultados, foi possível obter um quadro significativo de saberes e práticas coerentes. Além disso, o grande comprometimento da professora com o ensino na escola pública, visível tanto na sua atuação com os alunos como nos seus depoimentos, o seu posicionamento crítico, seu espírito inovador e criativo, que constituem o seu saber-ser, foram fatores fundamentais na configuração da prática pedagógica bem sucedida desta alfabetizadora.

PALAVRAS-CHAVE: Professor alfabetizador bem sucedido. Saberes. Práticas pedagógicas. Formação de professores.

\section{INTRODUÇÃO}

Apesar de investimentos na área educacional, o Brasil ainda apresenta indicadores educacionais bastante desfavoráveis, principalmente nas questões referentes à alfabetização. Massificação do ensino público, entrada da mulher no mercado de trabalho e ainda o desenvolvimento tecnológico são apontados, entre outros fatores, como "responsáveis" pela queda da qualidade do ensino ministrado, segundo nos aponta Esteve (1999). Os resultados dessa queda vêm sendo mostrados, ano após ano, nos exames nacionais e estaduais elaborados pelas políticas públicas (cujo objetivo é

\footnotetext{
${ }^{1}$ UNIARA - Centro Universitário de Araraquara. Curso de Pedagogia - EAD - Departamento de Ciências Humanas e Sociais. Araraquara - SP - Brasil. 14801-320 - lenitacml@gmail.com

${ }^{2}$ UNIARA - Centro Universitário de Araraquara - Departamento de Ciências Humanas e Sociais. Professora do Curso de Pedagogia e coordenadora do Mestrado Profissional em Processos de Ensino, Gestão e Inovação. Araraquara - SP - Brasil. 14801-320 - dcharara@ terra.com.br
} 
verificar o nível de aprendizagem dos alunos e, portanto, a qualidade do ensino na rede pública) bem como nas avaliações internacionais.

Pode-se dizer que houve um avanço nos resultados dos exames nacionais, embora ainda sejam insatisfatórios se comparados às metas estabelecidas pelo governo ano a ano e aos países da Organização para Cooperação e o Desenvolvimento Econômico (OCDE) que são os mais bem colocados do mundo em termos de qualidade da educação.

Em relação à última edição divulgada do Pisa (Programme for International Student Assessment) realizado em 2009, o Brasil ficou na $53^{\circ}$ posição entre 65 países. Embora os estudantes brasileiros tenham apresentado uma melhora em relação à Matemática e Ciências, o desempenho continua baixo nas três últimas edições dessa avaliação.

Essas avaliações, apesar de serem questionadas em vários aspectos (ênfase no produto, por exemplo), demonstram as dificuldades de aprendizagem dos estudantes brasileiros ao mesmo tempo em que fornecem indicações gerais sobre o desempenho das escolas estaduais.

Tendo em vista que a questão da alfabetização ainda constitui um problema grave em nosso país e considerando a existência de profissionais bem sucedidos no contexto adverso da escola pública, o objetivo geral deste estudo é descrever a trajetória profissional, analisar saberes e atividades que configurem a prática pedagógica da professora bem sucedida participante deste estudo, no sentido de entender as razões do seu sucesso na tarefa de ensinar. Queremos também verificar até que ponto existe uma correlação entre os saberes e as práticas identificados considerando as diferentes naturezas dos saberes e os condicionantes da prática pedagógica.

\section{O ESTUDO}

Para atingirmos o objetivo proposto, buscamos um referencial teórico sobre os saberes (TARDIF, 2002) e a prática docente (GIMENO SACRISTÁN, 2000).

Esta investigação tomou por base o conceito de prática pedagógica tal como proposto por Gimeno Sacristán (2000). Para ele, a prática pedagógica não pode ser compreendida se não estiver relacionada com o conceito de currículo definido como “[...] o projeto seletivo de cultura, cultural, social, política e administrativamente condicionado, que preenche a atividade escolar e que se torna realidade dentro das 
condições da escola tal como se acha configurado." (GIMENO SACRISTÁN, 2000, p.34). Por se tratar de um processo tão complexo, Gimeno Sacristán (2000) propõe seis níveis para a objetivação do currículo. O nível 4, currículo na ação: a arquitetura da prática, refere-se especificamente às tarefas/atividades do professor que, no seu conjunto, constituem sua prática pedagógica.

Segundo Gimeno Sacristán (2000), é na atividade dos professores e alunos que o currículo se concretiza. O "tempo de classe" é preenchido com tarefas escolares que podem ser traduzidas em atividades de ensino. Essas tarefas escolares configuram uma prática que nem sempre expressa as intenções e os conteúdos do currículo somente, pois sua estrutura obedece a múltiplos determinantes que não são apenas os curriculares.

Para o autor em questão, as tarefas escolares são o conteúdo da prática e, para compreender essa "arquitetura da prática", o autor propõe um sistema de análise das funções do professor que configuram, também, sua profissionalização.

Tão importante quanto analisar, descrever e identificar aspectos da prática docente é compreender como é adquirido o saber docente, o qual, assim como a prática docente, é parte da cultura de trabalho do professor. Entre os autores que se preocuparam em discorrer sobre os elementos constitutivos da cultura docente, mais especificamente sobre o saber docente, pode-se apontar Tardif (2002). Ao contrário de Gimeno Sacristán (2000) que busca descrever, identificar e analisar como se constrói a prática docente, Tardif (2002) busca compreender como o saber docente é adquirido e qual a natureza desse saber.

Diante da dificuldade em se conceituar cientificamente o que vem a ser o saber, Tardif (2002) faz uma associação da noção de saber com a ideia de exigências de racionalidade. Ou seja, saber alguma coisa ou fazer alguma coisa de maneira racional implica o sujeito ser capaz de responder a perguntas como "por que você diz isso?" e “por que você faz isso?”. Dessas aproximações, Tardif (2002, p.199) chama de saber “[...] unicamente os pensamentos, as ideias, os juízos, os discursos, os argumentos que obedeçam a certas exigências de racionalidade.” Isto é, o sujeito age racionalmente quando é capaz de justificar, por meio de argumentos, seu discurso ou ação diante de outro indivíduo que o questiona sobre a pertinência ou valor deles.

Sua preocupação é norteada por questões sobre quais são os saberes que servem de base ao ofício de professor, como são adquiridos, qual a natureza dos mesmos (saberes eruditos, conhecimentos técnicos, saberes de ação, de natureza artesanal, 
saberes racionais, ou se apoiam em crenças, valores e na subjetividade dos professores) e como os professores se relacionam com esses mesmos saberes.

Para ele o saber docente está ligado ao contexto profissional, relacionado aos elementos do trabalho docente, com todos os seus condicionantes. Fugindo ao mentalismo e ao sociologismo, sua abordagem procura "[...] situar o saber do professor na interface entre o individual e o social, entre o ator e o sistema, a fim de captar a sua natureza social e individual como um todo.” (TARDIF, 2002, p.16).

Segundo Tardif (2002), a relação dos docentes com os saberes não se reduz a uma mera função de transmissão dos conhecimentos já constituídos. A prática do professor integra diferentes saberes, com os quais o corpo docente mantém diferentes relações. Nesse sentido, o autor define saber docente como "[...] um saber plural, formado pelo amálgama, mais ou menos coerente, de saberes oriundos da formação profissional e de saberes disciplinares, curriculares e experienciais.” (TARDIF, 2002, p.36).

Desse conjunto Tardif destaca a importância dos saberes experienciais que se originam da prática cotidiana da profissão e são por ela validados. Tardif (2002, p.4849), define os saberes experienciais como "[...] conjunto de saberes atualizados, adquiridos e necessários no âmbito da profissão docente e que não provêm das instituições de formação nem dos currículos.” Não são saberes da prática. São saberes práticos que se integram a ela - prática - e dela são partes constituintes enquanto prática docente. Eles constituem a cultura docente em ação, portanto, pode-se dizer que é o saber do "como fazer".

$\mathrm{O}$ autor aprofunda o tema dos saberes, propondo um modelo tipológico que possibilite a identificação e a classificação dos saberes dos professores, sem compartimentá-los, chamando a atenção para as fontes de aquisição desse saber (saberes pessoais, saberes provenientes da formação escolar anterior, saberes provenientes da formação profissional para o magistério, saberes provenientes dos programas e livros didáticos usados no trabalho, saberes provenientes de sua própria experiência na profissão, na sala de aula e na escola) e o modo como se integram no trabalho do professor.

\section{PERCURSO METODOLÓGICO}


Os instrumentos e procedimentos utilizados caracterizam o presente estudo como uma pesquisa empírica, mais especificamente, um estudo de caso que, como afirmam Lüdke e André (1986, p.23), “[...] encerra um grande potencial para conhecer e compreender melhor a vida escolar."

O sujeito desta pesquisa é uma professora alfabetizadora bem sucedida com grande experiência nos anos iniciais do ensino fundamental na rede pública estadual de ensino e ainda atuante em sala de aula.

A justificativa para a escolha dessa professora apoiou-se nos seguintes critérios: a) o contato prévio com a prática pedagógica da professora durante os estágios de graduação da pesquisadora; b) o fato de ser uma profissional respeitada e considerada bem sucedida pelos pares, exercendo certa liderança entre eles; c) o reconhecimento da direção da escola pelo trabalho pedagógico que realiza.

Acrescente-se ainda o fato da profissional selecionada atuar num contexto educacional desfavorável, atendendo uma clientela de baixa renda e com faixa etária de 8 anos, num ambiente com escassez de recursos pedagógicos. É importante ressaltar que, apesar das condições materiais adversas, os alunos dessa escola obtiveram ótima pontuação em Língua Portuguesa, classificando-a acima da média paulista na prova do Sistema de Avaliação do Rendimento Escolar do Estado de São Paulo (SARESP) 2010.

Os resultados obtidos em campo surgiram das entrevistas, da observação das aulas, da coleta do material didático utilizado pela professora bem como de seu planejamento didático.

\section{RESULTADOS OBTIDOS}

As práticas pedagógicas observadas foram agrupadas de acordo com Gimeno Sacristán (2000) e os saberes identificados foram subcategorizados de acordo com Tardif, (2002).

Vieira (2007) e Cerdas (2012) já haviam pesquisado no Banco de Teses CAPES um conjunto de características de professoras alfabetizadoras, embora sem a preocupação de distinguir saberes de práticas, e que também foram observadas no fazer da professora participante deste estudo, dentre as quais, destacamos algumas a seguir: a) desafiam os alunos constantemente; b) sanam as dúvidas dos alunos; c) criam rotinas e rituais durante o desenvolvimento dos conteúdos e atividade; f) apresentam comprometimento com a aprendizagem do aluno evidenciado nas expectativas positivas 
quanto ao seu rendimento; g) reconhecem que os alunos considerados "mais lentos" necessitam de maior atenção, porém não apresentam atitudes preconceituosas; h) trocam experiências com colegas; i) combinam formação tradicional com aspectos de um ensino renovador.

Almeida (2013) aprofundou as pesquisas de Vieira (2007) e Cerdas (2012), identificando um novo conjunto de características de professoras bem sucedidas, dentre as quais destacamos: a) conferem grande valor ao dever de casa; b) compromisso com a aprendizagem do aluno; c) apresentam autonomia e segurança quanto a sua própria metodologia e aos recursos didáticos empregados; d) possuem clareza quanto aos objetivos das atividades realizadas em aulas; e) utilizam comportamentos dos alunos como forma de avaliar a consecução dos objetivos, reforçando comportamentos desejáveis;

Além das características mencionadas e já identificadas em estudo anteriores, outro conjunto de práticas específicas da professora investigada foi observado: a) utiliza espaços externos à escola; b) realiza algumas atividades fora da sala de aula/ao ar livre; d) organiza grupos, com alunos com diferentes níveis de aprendizagem; c) elabora avaliação concernente à aprendizagem do aluno, d) planeja o conteúdo da semana em conjunto com as demais professoras; e) adapta os materiais encontrados considerando as reais necessidades de seus alunos.

O mesmo ocorreu com os saberes já identificados em pesquisas anteriores e que foram confirmados na professora investigada: a) necessidade de inovar e modificar a prática de ensino; b) consciência da importância de não excluir nenhum de seus alunos; c) necessidade de diversificar as estratégias de ensino; d) necessidade de não discriminação da linguagem do aluno; e) consciência dos objetivos das atividades realizadas em aulas; f) utilização dos comportamentos dos alunos como forma de avaliar a consecução dos objetivos, elogiando comportamentos desejáveis.

Outros saberes específicos da professora investigada puderam ser acrescentados aos anteriormente mencionados: a) valorização da leitura como forma de motivação; b) aplicação de práticas vivenciadas em sua infância; c) responsabilidade do professor pelo processo de ensino; d) importância do trabalho em pares ou grupos sabendo lidar com a interação que se estabelece; e) necessidade de múltiplas formas de avaliação; f) consciência da importância da utilização dos diferentes espaços da escola; g) consideração da opinião da família sobre sua prática; h) distinção entre o que é 
contribuição teórica e o que prática pedagógica; i) consciência da importância de avaliar o aluno de acordo com seu nível de aprendizagem.

Apresentamos a seguir no quadro 1 uma tentativa de correlacionar um conjunto de saberes às práticas observadas:

\section{QUADRO 1- Coerência entre os saberes e as práticas da docente}

\begin{tabular}{|c|c|}
\hline Saber & Prática \\
\hline Necessidade de sair do espaço escolar com os alunos & Utiliza espaços externos à escola \\
\hline $\begin{array}{l}\text { Consciência da necessidade de trabalhar com atividades } \\
\text { diferenciadas para alunos com diferentes níveis de } \\
\text { conhecimento }\end{array}$ & $\begin{array}{l}\text { Oferece atividades diferenciadas para alunos com } \\
\text { maior dificuldade }\end{array}$ \\
\hline Valorização da leitura como forma de motivação & $\begin{array}{l}\text { Incentiva a prática de leitura lendo para seus alunos } \\
\text { todos os dias e permite que os alunos levem gibis para } \\
\text { casa }\end{array}$ \\
\hline $\begin{array}{l}\text { Consciência da insuficiência do material didático oferecido } \\
\text { pela escola para o desenvolvimento de sua prática }\end{array}$ & $\begin{array}{l}\text { Consulta livros didáticos, internet e outras fontes para } \\
\text { buscar material }\end{array}$ \\
\hline \multirow[t]{2}{*}{$\begin{array}{l}\text { Clareza de que seus alunos apresentam diferentes ritmos de } \\
\text { aprendizagem }\end{array}$} & $\begin{array}{l}\text { Prepara atividades diferenciadas para grupos de alunos } \\
\text { com dificuldades }\end{array}$ \\
\hline & $\begin{array}{l}\text { Organiza grupos, com alunos com diferentes níveis de } \\
\text { aprendizagem }\end{array}$ \\
\hline Importância da organização espacial & $\begin{array}{l}\text { Organiza o espaço da sala de aula de acordo com a } \\
\text { atividade a ser desenvolvida }\end{array}$ \\
\hline Importância do trabalho em pares ou grupos & Organiza algumas atividades em pares ou grupos \\
\hline $\begin{array}{l}\text { Necessidade de movimentar-se na sala de aula, atendendo } \\
\text { os alunos }\end{array}$ & $\begin{array}{l}\text { Movimenta-se o tempo todo em sala de aula } \\
\text { orientando e observando os alunos }\end{array}$ \\
\hline Utilização dos diferentes espaços da escola & $\begin{array}{l}\text { Realiza algumas atividades fora da sala de aula/ao ar } \\
\text { livre }\end{array}$ \\
\hline $\begin{array}{l}\text { Necessidade de compartilhar com os pares os saberes e } \\
\text { práticas e consciência da importância dessa troca }\end{array}$ & $\begin{array}{l}\text { Planeja o conteúdo da semana em conjunto com as } \\
\text { demais professoras do terceiro ano }\end{array}$ \\
\hline Necessidade de retomar conteúdos não bem compreendidos & $\begin{array}{l}\text { Volta a explicar quando percebe que os alunos não } \\
\text { compreenderam o conteúdo }\end{array}$ \\
\hline $\begin{array}{l}\text { Consciência da importância de avaliar o aluno de acordo } \\
\text { com seu nível de aprendizagem }\end{array}$ & $\begin{array}{l}\text { Elabora avaliação diferenciada para os alunos que } \\
\text { ainda não se encontram alfabetizados }\end{array}$ \\
\hline Necessidade de múltiplas formas de avaliação & $\begin{array}{l}\text { Avalia diariamente os alunos. Avalia os alunos por } \\
\text { bimestre (prova elaborada por ela). Prova bimestral } \\
\text { elaborada pela equipe de professores. Avalia os } \\
\text { cadernos dos alunos. Elogia os alunos quando } \\
\text { avançam na aprendizagem. Valoriza momentos de } \\
\text { avaliação individual }\end{array}$ \\
\hline
\end{tabular}

Fonte: Elaboração própria. 
O quadro 1, embora não contemple o conjunto total de saberes e práticas da professora, revela a grande coerência entre muitos de seus saberes e de suas práticas. Essa coerência certamente constitui um elemento importante no perfil de um profissional bem sucedido e demonstra a capacidade de reflexão sobre seu fazer com base em saberes adquiridos em diferentes momentos de sua trajetória profissional.

Embora a correlação entre saberes e práticas seja apontada como desejável no trabalho do professor, verificamos a impossibilidade de que essa correlação ocorra no conjunto das práticas e saberes identificados. Isso se justifica pela própria natureza da prática que, embora envolva um planejamento intencional, consciente, está sujeita a múltiplos condicionantes e se caracteriza por situações de imprevisibilidade. Existem alguns saberes cujas fontes sociais de aquisição são provenientes da família, do ambiente de vida, entre outros, que dificilmente podem ser observados de forma concreta na prática do professor embora a influenciem.

\section{CONSIDERAÇÕES FINAIS}

Considerando a existência de profissionais bem sucedidos no contexto adverso da escola pública, esta pesquisa visou descrever a trajetória profissional, analisar saberes e atividades que configuram a prática pedagógica da professora participante no sentido de entender as razões do seu sucesso na tarefa de ensinar bem como verificar até que ponto existe uma correlação entre os saberes e as práticas identificados considerando as diferentes naturezas dos saberes e os condicionantes da prática pedagógica. Práticas e saberes identificados em pesquisas anteriores foram confirmados e outros foram acrescentados.

Dentre nossas conclusões, salientamos que não apenas saberes e práticas integram o perfil de um professor bem sucedido. Algumas características pessoais como entusiasmo, tolerância, paciência, respeito às diferenças, etc. são também fundamentais na configuração do perfil desse profissional.

Acreditamos que uma possível contribuição desta pesquisa foi a tentativa de identificar os saberes e relacioná-los com suas origens, tal qual foi proposto por Tardif (2002), pois esse empreendimento permite entender melhor quais saberes a docente mobiliza na tarefa de ensinar, a trajetória bem sucedida, compreendendo não apenas o momento de sua formação profissional para o magistério, mas incorporando saberes pessoais, da formação escolar anterior, e, principalmente, os saberes originados da sua 
própria experiência na profissão. É preciso enfatizar a importância desse saber experiencial que faz com que o professor seja considerado não apenas como um aplicador de conhecimento produzido por outros pesquisadores, mas um sujeito capaz de gerar saberes sobre sua própria prática, como pôde ser observado na fala e na prática da docente investigada.

O quadro 1, que procura relacionar alguns saberes e práticas da professora investigada, é contribuição importante no sentido de confirmar que a coerência entre o saber e o saber-fazer é outro elemento desejável para um ensino eficaz. Embora tenhamos verificado a impossibilidade de que essa correlação ocorra no conjunto das práticas e saberes identificados.

Além da coerência entre seus saberes e práticas, como pode ser percebido no quadro 1 , o grande comprometimento da professora com o ensino na escola pública, visível tanto na sua atuação com os alunos como nos seus depoimentos, o seu posicionamento crítico, seu espírito inovador e criativo, que constituem o seu saber-ser, foram fatores fundamentais na configuração da prática pedagógica bem sucedida dessa alfabetizadora.

Nossa expectativa é que os resultados desta pesquisa possam contribuir para a área de formação de professores alfabetizadores na medida em que apresentam alguns aspectos fundamentais para uma prática pedagógica que promova a aprendizagem dos alunos, principalmente nos momentos iniciais da escolarização, que constituirão a base para as etapas escolares subsequentes.

\section{COHERENCE BETWEEN TEACHING KNOWLEDGE AND PRACTICES OF A SUCCESSFUL LITERACY TEACHER}

ABSTRACT: In spite of investments in educational field, Brazil still continues with serious problems, especially concerning issues related to literacy. To investigate the practice of successful teachers may offer relevant directions to the literacy teacher work, focus of this research. In this context, we have tried to analyze the coherence between teaching knowledge and activities/tasks which integrate the pedagogical practice of a successful teacher with the aim of understanding the reasons of her success in her teaching task. It is a case study with the following steps: a) search for fundaments; b) two semi-structured interviews; c) class observation; d) analysis of her textbooks as well as of her school planning. It was not possible to establish a strict correlation of all observed activities/tasks, with the identified teaching knowledge, considering that not all kind of knowledge must necessarily have a practical counterpart. Pedagogical practice, on the other hand, with all its constraints, in spite of planning, not always could be related to a teacher's knowledge in the classroom 
context, which is not always foreseeable. Considering this, it was possible to obtain a significant picture relating her teaching knowledge and her coherent practices. Besides this, her great compromise with teaching in public school, visible in her performance with the students, as well as in her speech, her critical position, her creative and innovative spirit, which constitute her "knowledge about how to be", were fundamental factors in the configuration of the pedagogical practice of this successful literacy teacher.

KEYWORDS: Successful literacy teacher. Teaching knowledge. Pedagogical practices. Teacher formation.

\section{REFERÊNCIAS}

ALMEIDA, L. C de. Saberes e práticas de uma professora alfabetizadora bem sucedida. 2013. 140f. Dissertação (Mestrado em Educação Escolar) - Faculdade de Ciências e Letras, Universidade Estadual Paulista, Araraquara, 2013.

CERDAS, L. Práticas e saberes docentes na alfabetização nos anos iniciais do ensino fundamental: contribuições de pesquisas contemporâneas em educação. 2012. 393f. Tese (Doutorado em Educação Escolar) - Faculdade de Ciências e Letras, Universidade Estadual Paulista, Araraquara, 2012.

ESTEVE, J. M. Mudanças sociais e função docente. In: NÓVOA, A. (Org.). Profissão professor. 2.ed. Portugal: Porto Ed., 1999. p.93-124.

GIMENO SACRISTÁN, J. O currículo: uma reflexão sobre a prática. Porto Alegre: ARTMED, 2000.

LÜDKE, M.; ANDRÉ, M. E. D. A. Pesquisa em educação: abordagens qualitativas. São Paulo: EPU, 1986.

TARDIF, M. Saberes docentes e formação profissional. 7.ed. Petrópolis: Vozes, 2002.

VIEIRA, L. C. As práticas das professoras alfabetizadoras como objeto de investigação. 2007. 157f. Dissertação (Mestrado em Educação Escolar) - Faculdade de Ciências e Letras, Universidade Estadual Paulista, Araraquara, 2007. 